\title{
Taras y desventuras de la figura del viejo entremesil de Quevedo
}

\author{
Esther Borrego Gutiérrez \\ Universidad Complutense de Madrid \\ Departamento de Filología Española II \\ Facultad Filología (edificio D). \\ Ciudad Universitaria. \\ 28040 Madrid \\ eborrego@ucm.es
}

[La Perinola, (Issn: 1138-6363), 22, 2018, pp. 21-38]

DOI: $10.15581 / 017.22 .21-38$

Para Álvaro Bustos Táuler

Super senes intellexi... $(P S, 118,100)$

\begin{abstract}
Como ya apuntó el genial Asensio ${ }^{1}$ y han reiterado numerosos estudiosos, los personajes entremesiles de Quevedo bien pueden parangonarse con los que pueblan las páginas de los Sueños, de El Buscón y de otras obras suyas de corte satírico. Su empeño por degradar al hombre con el fin de hacer patentes sus vergüenzas y vicios es la herramienta perfecta para lograr una sátira individual y social que incide agudamente en el modo de afrontar los eternos conflictos de la vida humana: el amor, el matrimonio, la ambición, la lucha entre hombres y mujeres, el paso del tiempo y la muerte inexorable. La degradación a la que somete Quevedo a sus personajes se hace más patente en ciertos tipos que han llegado prácticamente a convertirse en una suerte de iconos de su fábrica literaria. Todos ellos se inspiran en un hombre o una mujer con un problema que podemos denominar «real» pero que se resuelve finalmente por el peor camino, llegando a convertir a los implicados en seres grotescos y despreciables: así, la moza que busca marido que la mantenga se convierte en una buscona a la que solo interesa la bolsa del pretendiente de turno, pasando por encima de otras consideraciones más auténticas o espirituales; la mujer que soporta un tedioso marido, o bien traspasa peligrosamente el terreno del adulterio mediante agudos y disparatados ardides, o bien celebra por dentro su viudez mientras exhibe un fingido pesar en velatorios y funerales; lo mismo ocurre con otra de las «figuras» degradadas del amplio elenco quevedesco: el marido cor-
\end{abstract}

1. Asensio, 1971, pp. 181-182, 191-193. 
nudo, cuya simpleza raya con la necedad más patética, convirtiéndose en un pelele. Mucho se ha hablado de estos personajes pero menos de uno que bien puede anclarse en esta cadena de figurillas risibles y despreciables: el viejo que se resiste a serlo, que lucha irremediablemente contra su decadencia física en un vano intento de aminorar sus efectos visibles, con dinero o con inusitadas tretas cosméticas y de vestuario. Pero no se trata de una figura aislada en su ridículo, sino que sus vicios se ven potenciados por su antagonista, la mujer joven que se aprovecha de sus dádivas. Así, del mismo modo que la tomajona se complementa con el joven incauto que cae en sus garras, la prostituta con su rufián y la adúltera con el marido manso y crédulo, nuestro vejete se contrapone y a la vez se complementa con la mujer sometida a los peores vicios: embaucadora, manipuladora, hipócrita, mandona..., pero sobre todo incansable en su búsqueda de fortuna, por lo que el viejo será para ella una presa fácil. Se trata de uno de los personajes más denigrados del corpus quevedesco, pero no tanto como su equivalente femenino, la vieja, a cuyo afán por aparentar menos edad se añadirán componentes mucho más graves como su condición de dueña celestinesca, a veces la brujería, y siempre el desaliño, la suciedad y la repugnancia física. Baste un botón de muestra de uno de nuestros entremeses, del que se infiere que el paso del tiempo genera unos efectos corrosivos que Quevedo describe de forma más descarnada en las mujeres que en los hombres:

\begin{tabular}{ll} 
Carasa & \multicolumn{1}{c}{ ¿Qué son viejas? } \\
Juez & Unas niñas añejas, \\
que untadas y añadidas, \\
carreteras del tiempo, \\
quieren hacer cejar atrás las vidas, \\
dando a entender que pueden con engaños \\
hacia la cuna recular los años; \\
unas que, rucias, canas y desiertas, \\
se remiendan las sienes con las muertas \\
y pelando difuntas, \\
se ponen rizos y se añaden puntas, \\
y me dicen que está la corte llena \\
de guedejas en pena. \\
(Los enfadosos, en Teatro completo, pp. 385-386) ${ }^{2}$.
\end{tabular}

Pero no es solo que nuestro autor se cebe de manera inmisericorde en la vieja y lo haga de manera más, digamos, compasiva en el viejo, es que desde el punto de vista cuantitativo la figura de la mujer entrada en años está más presente que la del viejo en el teatro breve de Quevedo. Esta mayor presencia, unida a una intensidad mayor en la degradación, es quizá lo que ha propiciado que el personaje femenino haya merecido

2. Citaré todas las piezas dramáticas de Quevedo en el cuerpo del texto por la edición de Arellano y García Valdés, Teatro completo, 2011. Abrevio esta referencia como Teatro completo. 
mayor atención por parte de la crítica ${ }^{3}$. No queremos dejar de apuntar, aunque nunca podamos saberlo, hasta qué punto la supuesta misoginia de don Francisco, tan traída y llevada por la crítica, puede tener que ver con que el mayor peso de la balanza en la diatriba de la vejez mal llevada se lo lleve la mujer anciana y no su homólogo masculino. Si bien es cierto que su flecha se dirige preferentemente al blanco de las mujeres (de todas las edades), también es cierto que desde el punto de vista sociológico, y con visión de época, la mujer vieja era tristemente «inservible», toda vez que ya no era útil ni para engendrar ni para dar placer, y su vida discurría en la realidad por caminos no siempre dignos y fácilmente ridiculizables ${ }^{4}$. Por otra parte, aunque los matrimonios desiguales fueron un hecho y el afán por ocultar las señales del paso del tiempo es algo común a todos los tiempos, no creemos que en el caso de la sátira del viejo, de su conversión en "figurilla», esta sátira proceda solo de una realidad social y humana evidente, puesto que su deriva en los entremeses de Quevedo tiene detrás al menos un siglo de literatura y folklore. En este trabajo intentaremos perfilar los rasgos del viejo entremesil quevedesco, a partir de sus conocidos precedentes ruedescos y cervantinos, que servirán de base para la figura del «vejete» como personaje fijo en los entremeses de la segunda mitad del siglo $\mathbf{X V I I}^{5}$. En cuanto al entronque de esta figura con la realidad de la época, sí hay que apuntar que Quevedo, agudo observador de la realidad, se inspiró en un material vivo y candente: la muchedumbre que poblaba la corte. En efecto, el autor de Los Sueños exploró su vena satírica y hasta sarcástica en el diseño de ciertas figuras cortesanas, en el sentido de «habitantes de la Corte», que se convirtieron, ya deformados, en protagonistas de sus entremeses, eso sí, en un alarde grotesco de exhibición de sus carencias, ya físicas, ya morales o ya monetarias: el lindo, las damas de la corte, las viejas celestinescas, nuestros vejetes, entre otros: todos ellos dilapidan su tiempo y su dinero en mostrar una falsa fortuna o una belleza y juventud ya marchitas, contraviniendo así la naturaleza. No pueden ser más iluminadoras en este punto las palabras de Asensio:

3. Véase Arellano, 1984a, 1984b y 2012; Borrego, 2003; Hernández Vargas, 2015. Conviene recordar que la vieja en sus diversas manifestaciones (dueña, tercera, bruja) también está presente en la poesía satírica y burlesca, y en la prosa de los Sueños; recordemos el famoso pasaje del Sueño de la muerte en el que se denigra cruelmente a la dueña Quintañona, antonomasia de todas las dueñas, del que reproduzco un breve fragmento: «Con su báculo venía una vieja o espantajo [...] con una cara hecha un orejón; los ojos en dos cuévanos de vendimiar; la frente con tantas rayas y de tal color y hechura que parecía planta de pie; la nariz en conversación con la barbilla, que casi juntándose hacían garra» (Quevedo, Los sueños, ed. Arellano, pp. 373-374). Para nuestros intereses, por su correlato masculino, conviene destacar que la figura de la vieja que pretende aparentar juventud fue uno de los blancos preferidos en la prosa cómica de Quevedo; véase, por ejemplo, Quevedo, Prosa festiva, ed. Arellano y García Valdés, pp. 179 y 349. También Schwartz profundiza en la vetula como figura que aúna la tradición clásica y la recreación en Quevedo; véase Schwartz, 1986, pp. 161, 190 y 260.

4. Véase Borrego, 2003, pp. 1-2, 12.

5. Véase Borrego, 2002, pp. 187-189. 
en la medida en que cabían en el cerco frívolo del entremés, transportó a él sus chistes y alucinaciones, sus hallazgos lingüísticos y su perspectiva de la vida. Del previo arsenal de motivos, dos son los que traslada preferentemente a sus piezas: el del amor y el de la antinatura. El amor de la mujer es mercaduría. El vampiro sexual femenino esclaviza al hombre, le convierte en galeote de la familia que persigue el éxito familiar y sus símbolos: el coche, las joyas, los vestidos. El esfuerzo social se malgasta en apariencias, en negar la naturaleza simulando belleza y juventud que de hecho se compran en la tienda; nobleza y encumbramiento que se fingen remedando usos y costumbres de los favorecidos. Estas obsesiones, más complejamente expuestas en las obras mayores, encarnan, al modo frívolo del entremés, en una galería de figurillas cómicas ${ }^{6}$.

Sin embargo, este desfile de personajes ridículos procedentes de diversas tradiciones literarias pero con una buena carga de costumbrismo no es original ni exclusivo de Quevedo. En este sentido, y ya en referencia a la figura del viejo, no podemos dejar de mencionar el teatro de Lope de Rueda y el de Cervantes, autores considerados precedentes del teatro quevedesco, que introducirán esta figura por diferentes caminos, sobre todo el segundo. Nos detendremos brevemente en Lope de Rueda, que apenas presenta al personaje como tal, sino asimilado a otros tipos. No obstante, sí podemos comprobar cómo alguna que otra figura de sus Pasos identificada como «viejo»-explícito o no- sí ostenta ciertos rasgos negativos que se desarrollarán con plenitud en los entremeses posteriores; es el caso del avaricioso Lucio, experimentado médico del paso tercero de El deleitoso, que se aprovecha económicamente del simple Martín de Villalba ayudando a que su mujer siga poniéndole los cuernos; o de Gerardo, del paso de Guiomar, Clavela y Julieta ${ }^{7}$, que aparece puntualmente como padre de Clavela y amo de la negra Guiomar, con una trivial actuación inicial. Será un paso de amplias raíces folklóricas, Las aceitunas, el que presentará al personaje como tal: “Toruvio, viejo», junto a su mujer, "Águeda de Toruégano», que lo lleva a mal traer. El hecho de que en el propio dramatis personae se indique expresamente la condición de «viejo» de Toruvio hace suponer una caracterización concreta y cómica de vestuario e incluso accesorios (¿bastón?). El matrimonio no está precisamente bien avenido pues ya desde el principio el hombre dice para sí: «¿Qué os terná aparejado de comer la señora de mi mujer? iAsí mala rabia le mate!»», a lo que se suman ciertas expresiones denigratorias de la mujer hacia él. Ambos se enzarzan en una discusión absurda acerca del rédito que disfrutarán en un futuro utópico de un renuevo de aceituna plantado recientemente por el marido, que se manifiesta como un rematado necio durante la escena. Ante la intervención de un vecino, la mujer acusa injustamente

6. Asensio, 1971, p. 226.

7. Véase Lope de Rueda, Pasos, ed. Canet, pp. 225 y ss.

8. Lope de Rueda, Pasos, ed. Canet, p. 163. 
a Toruvio, cuya bobaliconería queda más patente: «iAy señor! Este mal hombre que me quiere dar las cosas a menos precio y quiere echar a perder mi casa. iUnas aceitunas que son como nueces!» ${ }^{9}$. Otra pieza que indica expresamente la condición de «viejo» de uno de los personajes, Socrato, es el Paso de Pablos Lorenzo y de Ginesa, su mujer ${ }^{10}$; aquí actúa en un par de ocasiones de criado conciliador del simple Pablos y de su aguerrida mujer Ginesa. En Los ladrones, sí figura explícitamente un personaje, “Cazorla», como "viejo ladrón»" que da lecciones del oficio a sus compañeros, lo que refuerza la idea de que el viejo no desempeñaba un rol específico sino que se identificaba con personajes bien tipificados del elenco de Rueda, como el simple, el criado, el doctor o, en este caso, el rufián ${ }^{12}$.

Miguel de Cervantes introduce de lleno la figura del viejo malcasado en uno de sus entremeses, El juez de los divorcios. El (vejete», así denominado en el dramatis personae, es acusado por su mujer, Mariana, de «impertinencias»y «enfermedades, que son sin número»:

Muy buen dote llevé al poder desta espuerta de huesos, que me tiene consumidos los días de la vida. [...] El ivierno de mi marido y la primavera de mi edad; el quitarme el sueño por levantarme a media noche a calentar paños y saquillos de salvado para ponerle en la ijada; el ponerle, ora aquesto, ora aquella ligadura, que ligado le vea yo a un palo por justicia; el cuidado que tengo de ponerle de noche alta la cabecera de la cama, jarabes lenitivos porque no se ahogue del pecho; y el estar obligada a sufrirle el mal olor de boca, que le güele mal a tres tiros de arcabuz ${ }^{13}$.

Sin embargo, el hombre se defiende atacando a la mujer: «veintidós años ha que vivo con ella mártir [...] y ya va para dos que me va dando vaivenes y empujones hacia la sepulturas ${ }^{14}$; por lo que el juez no accede al divorcio, ya que comprueba que ella sí le quiso cuando se casaron. De esta forma se logra salvar la figura del viejo dando un giro a la clásica humillación del personaje, pues este carece de vicios fuera de sus dolencias físicas, de las que, por cierto, él no tiene culpa. Así se defiende el pobre hombre de las desmesuras de su mujer:

9. Lope de Rueda, Pasos, ed. Canet, p. 165. Canet, p. 55, lo incluye en la categoría de simple o bobo.

10. Lope de Rueda, Pasos, ed. Canet, pp. 258 y ss.

11. Lope de Rueda, Pasos, ed. Canet, p. 295.

12. En varios pasos de Rueda aparece el amo avaricioso que mata de hambre a sus criados. Es el caso de Salcedo, de los pasos primero y segundo de El deleitoso, y de Dalagón, del sexto paso del Registro de representantes. No tenemos datos para confirmar la condición de viejo de esos personajes, pero los rasgos negativos del viejo avaricioso y de estos amos es plenamente coincidente.

13. Cervantes, Entremeses, ed. Asensio, pp. 62-63.

14. Cervantes, Entremeses, ed. Asensio, p. 63. 
y pues comisteis las maduras, gustad de las duras, que no está obligado ningún marido a tener la velocidad y corrida del tiempo ${ }^{15}$.

No es tan indulgente Cervantes con Cañizares, el viejo casado con Lorenza, la niña de El viejo celoso, que reúne en su persona no solo los achaques físicos del anterior sino los peores defectos, entre ellos los celos:

Siete puertas hay antes que se llegue a mi aposento, fuera de la puerta de la calle, y todas se cierran con llave [...] Y más, que toda la noche anda como trasgo por toda la casa ${ }^{16}$.

El mismo Cañizares reconoce que tiene celos «del sol que mira a Lorencita, del aire que le toca, de las faldas que la vapulean» ${ }^{17}$. Como es sabido, el viejo acaba burlado mediante el «engaño a los ojos» y el entremés acaba con música y baile. No es difícil adivinar lo frívolo y festivo del tratamiento del triángulo amoroso formado por la niña, el galán y el marido viejo, del que mucho se ha hablado poniéndolo en parangón con el carácter si cabe trágico de la novela cervantina El celoso extremeño, similar en trama y personajes y cuya precedencia al entremés es discutida. En todo caso, la figura del viejo entremesil sigue aquí la tradición folklórica y popular de la relación entre un hombre viejo y celoso y su joven esposa malcasada que busca un respiro fuera de los muros del hogar. Y es que el personaje, ya en los comienzos del XvII, es heredero de una amplia tradición literaria y resultará crucial en las piezas de burlas eróticas ${ }^{18}$.

La crítica del último tercio del siglo xx y lo que llevamos del xxi ha convenido en el papel central que ostentó don Francisco de Quevedo en el desarrollo del género, y de esta manera se le ha considerado un autor de transición entre Lope de Rueda y Cervantes y el entremesista barroco más famoso, Quiñones de Benavente, considerado generalmente el «padre del entremés». Hasta qué punto Quevedo tuvo en mayor o menor consideración sus piezas entremesiles es algo imposible de clarificar y no se puede achacar a la pérdida y dispersión de esos textos, pues era algo que ocurría habitualmente con este teatro, considerado más de “consumo» en las tablas que destinado a la impresión y a la lectura. Lo que es obvio es que no se dedicó al género de manera prioritaria y sí se comprueba cierto desprecio al mismo en sus constantes diatribas contra la comedia nueva -y sobre todo contra los (malos poetas»-, pero también es cierto que entre 1608 y 1631, años en los que escribió sus obras maestras, sí se empleó de modo paralelo en la escritura dramática,

15. Cervantes, Entremeses, ed. Asensio, p. 63.

16. Cervantes, Entremeses, ed. Asensio, p. 206.

17. Cervantes, Entremeses, ed. Asensio, p. 209.

18. Huerta Calvo, 1985, p. 38: «Rey destronado del Carnaval, cumple indefectiblemente el papel de marido cornudo, y se le asocia con la enfermedad (hernia, sífilis), la impotencia sexual y hasta con la muerte». 
y no solo en comedias más o menos de encargo o circunstancias sino en «ejercicios entremesiles que parecen responder mejor a sus gustos y habilidades de gran inventor del lenguaje y genio de la caricatura ${ }^{19}$. En todo caso, sí parece que ha influido en esa pérdida de una buena parte de su corpus entremesil la consideración de estas piezas como cosa menor frente a la calidad indiscutible de su prosa y de su poesía. A esto se suman otras razones que expone Asensio ${ }^{20}$, como la declaración de la Inquisición en 1632 acerca de la condición de espurias de las obras impresas de Quevedo antes de 1631 y la prohibición de publicarlas sin ser reconocidas y corregidas por el autor; a lo que se suma la dispersión de sus escritos durante sus temporadas de privación de libertad y tras su muerte. Todo esto nos lleva a la conclusión de que lo que nos queda es una pequeña muestra del teatro breve quevedesco, eso sí, representado en pleno siglo xviI y seguro que recibido con expectación viniendo de quien venía. No entro en problemas de atribución ni de delimitación del corpus de teatro breve de Quevedo, ya estudiado por críticos con reconocida solvencia ${ }^{21}$, y me ceñiré solo a los entremeses que sirvan a mi propósito, seleccionados entre los trece de (casi) segura atribución ${ }^{22}$. Así, la figura del viejo aparece con más o menos protagonismo -a veces simplemente citada- en: Diego Moreno, La vieja Muñatones, El marión, El marido pantasma, La venta, La ropavejera, Los enfadosos y Los refranes del viejo celoso. No aparece en Bárbara, El niño y Peralvillo de Madrid, La destreza, El caballero de la Tenaza y La polilla de Madrid.

En el elenco de títulos que de un modo u otro se acercan a la figura del viejo hemos de reconocer los dos extremos en cuanto al peso

19. Arellano y García Valdés, 2011, p. 15.

20. Asensio, 1971, pp. 178-179.

21. Damos por buena la fijación del corpus entremesil quevedesco que proponen Arellano y Valdés, 2011, que tienen en cuenta la de Blecua, 1981, pp. 9-15. Los estudiosos parten a su vez de las opiniones de La Barrera, 1860; Cotarelo y Mori, 1911; Fernández-Guerra, 1921; Artigas, 1927; Astrana Marín, 1932; Cotarelo Valledor, 1945; Mancini, 1955; Buendía, 1958; Crosby, 1967, y Asensio, 1971. Hay que aclarar que de los doce entremeses que edita Blecua, hay tres (Bárbara, Diego Moreno y El marión) que tienen segunda parte, por lo que en rigor él cuenta con quince entremeses quevedianos. Sáez Raposo y Huerta Calvo, 2008, p. 185, confirman este corpus y hacen notar las dificultades de su establecimiento definitivo. Arellano y Valdés, 2011, incluyen en su edición este corpus (aunque editan los tres dobles como un único entremés con dos partes) y añaden El caballero de la Tenaza, de lo que resultan los trece entremeses que hemos tenido en cuenta. En la mayoría de los casos se muestran reservas a la autoría de Los refranes del viejo celoso. Arellano y García Valdés también incluyen en su Teatro completo la comedia Cómo ha de ser el privado, Pero Vázquez de Escamilla y Fragmento en el reverso de una carta. Me centro en el corpus entremesil y dejo asimismo de lado los bailes, también editados en Teatro completo, pues apenas aportan nada al objeto de este estudio.

22. Los escritos en prosa (primera y segunda parte de Bárbara y Diego Moreno y La vieja Muñatones) son los más antiguos, de corte más folklórico y literario, y suelen fecharse entre 1608 y 1613 (Sáez Raposo y Huerta Calvo, 2008, p. 185). El resto están escritos en verso y se compusieron entre 1623 y 1627 (Jauralde Pou, 1998, pp. 492-493). Arellano y García Valdés, 2011, p. 13, creen que la escritura de su teatro tuvo lugar aproximadamente en el periodo 1613-1631. 
del personaje en la obra: desde el entremés en el que apenas hay una alusión al viejo verde o turpis senex, El marido pantasma ${ }^{23}$, a la pieza en la que es el absoluto protagonista, Los refranes del viejo celoso. Nótese que se trata de dos defectos bien diferenciados, pero ambos propios del vejete entremesil: la lascivia y los celos. A estas taras morales se sumarían la avaricia (que en este caso llega al hurto), la hipocresía y la ridícula obsesión por el honor; y en el ámbito de las desventuras físicas, la enfermedad y los achaques de la vejez, que intentarán disimularse por todos los medios. En todos los casos la muestra de estas carencias morales no responde tanto a una intención satírica única como a una vía de explotación del humor a través de tales defectos. Veamos.

La lascivia es el defecto menos explotado en este corpus; además de la citada alusión bíblica en El marido pantasma, que no deja de ser anacrónica, contamos con el discurso de la inefable dueña Gutiérrez de Diego Moreno (primera parte), que exhorta a Justa a aprovecharse de cada hombre que se le acerque, con su «arte rapativo». En la larga lista de incautos figuran los «viejos verdes» -expresión idéntica a la de $E l$ marido pantasma, por cierto-, a los que sí conviene acercarse dado su holgado bolsillo:

Y es que tú no has de desechar ripio. De cada uno toma lo que te diere; así, del carnicero carne, como del especiero especias, del confitero dulces, del mercader vestidos, del sastre hechuras [...] unos viejos verdes, estos son los que importa al arte rapativo que profesas (Teatro completo, pp. 329-330).

Quevedo retoma del corpus cervantino los celos del viejo entremesil, que se apuntan levemente en Diego Moreno (segunda parte), cuando el pretendiente de la joven viuda Justa, Landínez, se lamenta de que ella haya elegido a Diego Verdugo para casarse en vez de a él, decisión que achaca a la juventud del galán. De aquí deducimos que Landínez podría asumir el personaje de viejo con recursos económicos, pues Justa ya había aceptado sus favores en un tiempo anterior:

\begin{tabular}{|c|c|}
\hline LANDÍNEZ & ¿Otro marido? ¿Y conócesle tú? \\
\hline Paje & $\begin{array}{l}\text { Sí, señor. Diego Verdugo es, aquel de quien anduvo } \\
\text { vuesa merced celoso. }\end{array}$ \\
\hline LANDínez & $\begin{array}{l}\text { Y de quien ella siempre me dijo que le aborrecía } \\
\text { como al diablo. iAh, mujeres! }\end{array}$ \\
\hline Paje & $\begin{array}{l}\text { Luego ¿da vuesa merced crédito a palabras destas } \\
\text { señoras? }\end{array}$ \\
\hline ANDÍn & $\begin{array}{l}\text { Con todo eso no lo creo. Y si ella se ha casado con } \\
\text { Verdugo, ella ha buscado a quien lo sea de su ju- }\end{array}$ \\
\hline
\end{tabular}

23. «Señor, tú que libraste / a Susana inocente de los viejos» (Teatro completo, p. 468). Alusión al pasaje bíblico del Libro de Daniel en el que dos viejos espían a la joven Susana mientras se baña y la acusan de adulterio tras haberlos rechazado. Véase también Arellano y García Valdés, 1997, p. 54. 
ventud, porque yo le... Y a fe que él la haga andar tan justa como el nombre.

(Teatro completo, pp. 352-353)

Pero el entremés quevedesco de celos por antonomasia no es otro que Los refranes del viejo celoso, cuyo título es una variante ampliada del famoso entremés cervantino. A pesar de las dudas que han pesado históricamente sobre su atribución, varios críticos convienen en que el estilo bien podría ser de Quevedo. Se trata de una de las piezas teatrales breves más conocidas y graciosas; al parecer, disfrutó de gran fortuna, pues inspiró a entremesistas como Suárez de Deza y al mismo Calderón ${ }^{24}$. Se trata de una mascarada cómica en toda regla, con ciertos rasgos de mojiganga por el desfile grotesco de disfrazados, que recupera personajes de Los Sueños, en concreto de El sueño de la muerte, como ya hiciera notar Asensio ${ }^{25}$. Los tipos proverbiales que desfilan por las páginas del entremés y que castigan al vejete sin paliativos son, a saber, Calaínos, el Rey que rabió, el Rey Perico, Como dijo el otro, Villadiego, Juan de la Encina, Perico el de los Palotes, Maricastaña, la dueña Quintañona y Pero Grullo $^{26}$. Pero el protagonista del triángulo amoroso es el «Vejete»-que así figura en el elenco de personajes-, casado con doña Justa, quien es galanteada a su vez por el gracioso Rincón. El entremés comienza con un diálogo entre los jóvenes, en el que son perfectamente definidos los celos patológicos del anciano, que llega incluso a la agresión física ante cualquier dádiva ofrecida a su mujer:

$\begin{array}{ll}\text { Justa } & \begin{array}{l}\text { iAy Rincón! Yo gustara que me amaras } \\ \text { porque de noche a ratos me hablaras, } \\ \text { mas no tengo lugar y así te dejo, } \\ \text { que estoy casada con celoso y viejo. }\end{array} \\ \text { Rincón } & \text { ¿Qué tan viejo? } \\ \text { Justa } & \text { Tan viejo que te juro }\end{array}$

24. Calderón de la Barca es autor de un hilarante entremés de tema similar titulado Las carnestolendas (Lobato, 1989, pp. 430-450). Igualmente, El milagro, de Vicente Suárez de Deza, tiene como protagonista a un viejo celoso cuya joven mujer y sus amantes urden la treta de aparecer como figuras del más allá para lograr escaparse (Borrego, 2000, pp. 204-219). Es evidente que una de las fuentes inmediatas de estas piezas es, además de El viejo celoso, La cueva de Salamanca, con la diferencia sustancial de que ahí el marido no es un vejete, sino un manso marido, un «maridillo», que dirían Arellano y García Valdés (Teatro completo, pp. 62,63).

25. Véase Asensio, pp. 228-229.

26. La profusa anotación de Arellano y García Valdés (Teatro completo, pp. 543-561) nos permite reconocer la presencia de estos personajes en el Sueño de la muerte y en otros contextos literarios y folklóricos, asunto que excede los márgenes de este trabajo. Estos personajes a su vez aluden a otros también proverbiales, como Mateo Pico o Marta con sus pollos. 


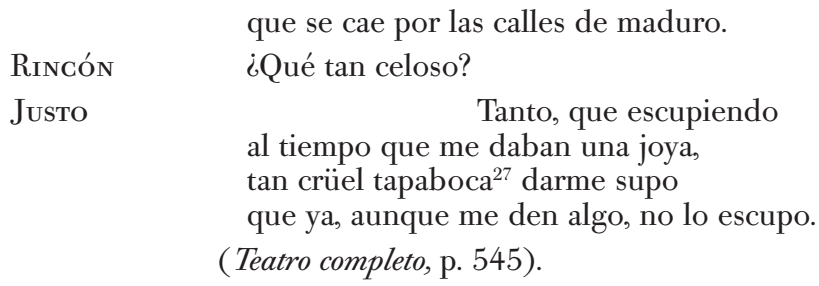

Tras un acerbo diálogo entre Justa y el vejete, provocado por los celos, comienza el desfile de personajes grotescos, que atacan al hombre con diversos calificativos, a cada cual más jocoso: Rincón, disfrazado de botarga, alude a su postración física llamándole «viejo clueco, viejo clueco $^{28}$ » (Teatro, p. 550); Villadiego es más compasivo y le llama «viejecito» (Teatro, p. 551), y Juan del Encina, en un tono también conciliador, (amigo» (Teatro, p. 552). Perico de los Palotes encabeza otra reata de insultos denominándole “endiablado viejecito» (Teatro, p. 553), al que sigue el Rey que rabió, que le llama «vejete engreído / con las barbas vitorianas / y el cabello dominico» (Teatro, p. 556). El Rey Perico, por su parte, le llama «vejete malvado» (Teatro, p. 560), y finalmente, Pero Grullo le califica de "viejo caduco y maldito» (Teatro, p. 560). Dejamos por ahora los insultos alusivos al declive físico y enumeramos los vicios morales: además de celoso, el vejete es endiablado, engreído, malvado y maldito.

En esta línea de degradación moral nos encontramos otra pieza protagonizada por un hombre viejo, en este caso, Corneja, un ventero ladrón, curiosamente caracterizado como «Vejete» en la acotación inicial del entremés de La venta, el más costumbrista del corpus quevediano ${ }^{29}$. De la venta, solo sabemos que está camino de Granada ${ }^{30}$ y que está regentada por Corneja, bajo cuyo mando está la moza Grajal, descarada criada cómplice de sus fechorías. La presentación del viejo alude a su hipocresía, pues, además de llevar un rosario $^{31}$ en la mano, está rezando:

27. tapaboca: «El golpe, que se da en la boca con la mano abierta o el que se da con el botón de la espada en la esgrima» (Aut). La segunda acepción no ofrece connotaciones de agresión física: «Metafóricamente se llama la razón, dicho o acción, con que a otro se le corta, y suspende la conversación, obligándole a que calle: especialmente cuando se le convence de ser incierto lo que dice» (Aut). Por el contexto, parece que el hombre ha golpeado a la mujer.

28. Clueco: «Dicho de una persona, muy débil e impedido por la vejez» (DLE).

29. Según Asensio, es la única pieza «costumbrista» del corpus entremesil quevediano (Asensio, 1971, pp. 231-232). Se compuso entre 1616 y 1619 y pudo estar destinado a las fiestas de Lerma de 1617 (ver Hernández Araico, 2004, p. 217).

30. La compañía de Guevara para en la venta, y este dice: «A representar vamos a Granada» (Teatro completo, p. 417).

31. Tanto el nombre como el atributo del rosario son despectivos, el primero como ave de mal agüero y el segundo como símbolo de la hipocresía. Ver Arellano, en Teatro completo, p. 404, donde se indica otros lugares de la obra de Quevedo en los que el rosario tenía esa connotación, como en La vieja Muñatones: “Componga esa capa, entorne esos 


\author{
Sale ConneJA, vejete, con un rosario $[\ldots]$ \\ Corneja Mas líbranos del mal, amén, Jesús. \\ (Teatro completo, p. 404).
}

Este comienzo no puede producir más que hilaridad, pues el público conoce perfectamente la calaña de su protagonista: la figura del viejo con el rosario y rezando mecánicamente oraciones vocales posee una vis cómica indiscutible ${ }^{32}$ Y es que nada más lejos de esa piedad fingida lo que enseguida comprobaremos: su avaricia sin límites, pues su negocio se basa en el engaño y en el fraude con el único fin de lucrarse a costa ajena, como le recuerda constantemente Grajal. El engaño tiene además un toque siniestro, como “corneja» que es, pues da de comer a los huéspedes animales malditos, como lechuzas (haciéndolas pasar por pollos) y ratones:

GRajal $\quad \begin{aligned} & \text { ¿Qué harán las ollas } \\ & \text { donde las lechuzas } \\ & \text { pasan por pollas }\end{aligned}$
$\quad[\ldots]$
Quien temiere ratones
venga a esta casa,
donde el güésped los guisa
como los caza (Teatro completo, p. 405).

Su condición de ladrón es tan evidente que Grajal le acusa de «barrer las bolsas y regar el vino» (Teatro completo, p. 407), para cantarle después la siguiente copla:

Grajal Ventero murió mi padre,

Satanás se lo llevó, porque no piense el infierno

que hubo solo un mal ladrón (Teatro completo, p. 407).

En todo caso, creemos que en este entremés confluye la figura del ventero con fama de ladrón con la figura del vejete, del mismo modo que apuntamos con algunas figuras de los Pasos de Lope de Rueda, en

ojos, amortezca la cara, y el rosario en la mano columpiando las cuentas. Y al salir de la puerta por los vecinos, una retahíla de amenes».

32. La figura del viejo es de una comicidad verbal y escénica patentes, y de estas líneas se infiere que tanto lo que dice como lo que hace persigue fundamentalmente la risa del espectador. Aunque este trabajo no se centre directamente en los mecanismos de comicidad de la figura del vejete, he tenido presente el excelente artículo de Maestro (2008) al abordar el tratamiento no solo lingüístico sino referencial y escénico del personaje. En esta línea, también he intentado matizar las diversas formas del humor en cada pasaje: no es lo mismo parodia que sátira ni caricatura que chiste, ni, por supuesto, lo grotesco equivale exactamente a lo ridículo. Para el estudioso, la caricatura «es la figura más recurrente de la materia cómica» en los entremeses quevedianos (Maestro, 2008, p. 82). 
las que el vejete no aparece como tal sino asimilado a personajes como el simple, el médico, el padre de una moza, el criado y, en una ocasión, como un rufián, llamado Cazorla, al que tipifican como «viejo ladrón». Del mismo modo que Rueda unifica los personajes del rufián y el vejete, Quevedo hace lo propio con los del ventero ladrón y el vejete. En todo caso, la avaricia y el latrocinio quedan bien subrayados en los insultos que el Estudiante profiere en la parte final de la pieza:

\begin{tabular}{|c|c|}
\hline Estudiante & $\begin{array}{l}\text { En esta pobre choza } \\
\text { todos somos hurtados sin Mendoza. }\end{array}$ \\
\hline Corneja & ¡Miente, miente el picaño! \\
\hline Estudiante & $\begin{array}{l}\text { ¿Ladrón, protoladrón, archiladrillo } \\
\text { y tátara Pilatos, } \\
\text { casamentero infame } \\
\text { de estómagos y gatos! }\end{array}$ \\
\hline Corneja & iInfame, espera, calla! \\
\hline Estudiante & $\begin{array}{l}\text { Que quien no mata con morcilla rala } \\
\text { menos me matará con una bala. } \\
\text { (Teatro completo, p. 418). }\end{array}$ \\
\hline
\end{tabular}

Otra amalgama de este tipo es la de la figura del viejo con la del padre desconfiado que guarda la honra de su hija, si bien en el caso de El marión, la fusión de las figuras resulta si cabe aún más burlesca porque el padre es custodio de la honra de su hijo varón, de lo que resulta una ridícula inversión de personajes y valores que prosperó en un conocido entremés de Quiñones de Benavente de título similar: Los mariones. Así, ya en el dramatis personae aparece «Un viejo, padre de don Constanzo' (Teatro completo, p. 483), un ridículo 'doncello ${ }^{33}$ que huye de los requiebros de varias mujeres, teme las opiniones de los demás sobre su honra e intenta ocultar a su padre la ronda de mujeres a la que se ve sometido, en clara parodia de los tópicos de las comedias y dramas de honor coetáneos. Se trata de un vejete burlesco que se ofende porque a su hijo lo han asaltado tres mujeres; es «el mundo al revés», lo que nos puede dar idea de que esa pieza bien pudo representarse en un entorno carnavalesco o similar:

$\begin{array}{ll}\text { Padre } & \text { iOh villano! ¿Así mi honor se trata? } \\ \text { Don Constanzo iTénganlo, [mis] señoras, que me mata! }\end{array}$

33. Neologismo quevedesco. En este mismo entremés: «porque no es bien que tomen los doncellos, / que suelen sucederles mil desgracias» (Teatro completo, p. 486); «Todo se ha trocado ya, / todo al revés está vuelto: / las mujeres son soldados / y los hombres son doncellos» (Quevedo, Poesía original, núm. 697). Nótese la alusión al mundo al revés en estos versos y el entorno de representación que proponemos para el entremés. 


\author{
Áselo por un brazo. \\ Padre Ven acá, ¿han quitádote tu honra? \\ Don Constanzo Ni por pienso. \\ PAdRe Di la verdad o perderás la vida. \\ Don Constanzo Maldito sea yo si una mano me han tocado.
}

(Teatro completo, p. 492).

De los vicios pasamos a las carencias físicas. La más dolorosa es la enfermedad que trae aparejada la vejez pero que, desgraciadamente, no suele ablandar a las mujeres sino más bien provocarles aún más rechazo; estos hombres suelen ser el blanco del ataque despiadado de sus jóvenes esposas. En Diego Moreno (primera parte), el doctor Musco, que no está caracterizado explícitamente como vejete, sí parece verse afectado por los achaques de los años. A Justa le resulta indiferente su enfermedad y solo le importa si le va a regalar algo:

Justa: $\quad[\ldots]$ ¿Cómo le va de salud, señor doctor?

Doctor: Ando algo némulo y corrompido, que tengo en el estómago una dureza y queríalo gastar.

Justa: ¿Qué es dureza? Me diga, porque cosa de gastar no puede ser mala.

Doctor: Como oyó de su gastar, entendió que eran monedas. Es una redundancia de la biles mal colta.

Justa: $\quad$ iPues sí!... Eso gástelo en otras cosas. Pensé que eran dineros.

(Teatro completo, pp. 333-334).

Pero el anciano más achacoso de todos es el protagonista de Los refranes del viejo celoso, increpado sin piedad por su mujer. Lejos de inspirar compasión, los papeles se invierten y es la mujer la que transmite una imagen de crueldad y escarnio ${ }^{34}$ ante la incapacidad física de su marido. Quevedo recupera así dos viejos cervantinos, el pobre esposo viejo y enfermo de Eljuez de los divorcios ${ }^{35}$ y el Cañizares de El viejo celoso, cuyas esposas u otras mujeres que les rodean también se despachan a gusto ${ }^{36}$. Pero veamos a nuestra Justa en pleno arrebato de cólera:

34. Según Maestro, el escarnio, entendido como una "agresión ad hominem» es "una forma muy frecuente de comicidad en la obra de este autor» (Maestro, 2008, p. 84).

35. Véase supra la cita del entremés, en la que la esposa se lamenta de las enfermedades de su viejo marido, en concreto, ijada, hernia, bronquitis o pulmonía («para que no se ahogue del pecho») y hasta mal aliento. Ijada: "cada una de las dos cavidades simétricamente colocadas entre las costillas falsas y los huesos de las caderas»; también tiene la acepción del «dolor o mal que se padece en la ijada» (DLE).

36. “Cristina: iJesús y del mal viejo! Toda la noche: “Daca el orinal, toma el orinal; levántate, Cristinica, y caliéntame unos paños, que me muero de la ijada: dame aquellos juncos, que me fatiga la piedra". [...] iPux, pux, pux, viejo clueco, tan potroso como celoso, y el más celoso del mundo! Lorenza: Dice la verdad mi sobrina» (Cervantes, Entremeses, ed. Asensio, p. 204). 
Doña Justa Sois un vejete clueco, hecho de barro, depósito de tos y del catarro, alma de güeso, que por miserable penando está en braguero perdurable, todo refranes, como el dueño, güeros.

(Teatro completo, p. 549).

La expresión «viejo clueco», de raíces folklóricas ${ }^{37}$ y ya empleada por Cervantes, alude a sus desarreglos escatológicos y a la enfermedad de la potra o hernia ${ }^{38}$, para la que se necesita un braguero ${ }^{39}$; además, el hombre debe de estar en los huesos («alma de güeso») y constantemente resfriado (“depósito de tos y del catarro»). A estos males se une otro si no más desagradable, sí más ridículo, pues Justa le cuenta a Rincón que su marido habla “con visajes» (Teatro completo, p. 542), que en sentido denotativo son, sin más, expresiones del rostro, pero que en ocasiones pueden aludir a movimientos anormales producidos por la edad o la enfermedad, una especia de espasmos ${ }^{40}$.

Pero el viejo enfermo no es satirizado de una forma tan cruel como el viejo presumido, que pretende remediar los efectos visibles de la edad sin conseguir otro resultado que la triste y cómica parodia de sí mismo. En La vieja Muñatones entra en escena Cardoso describiendo su llegada a la corte:

La arena con el puente, el río con polvo; mujeres que piden, hombres que arrebatan un fardo por cuello, un cuello por puño; más barrigas en los hombres que en las mujeres, colchones por pantorrillas (Teatro completo, p. 360).

En este contexto de enumeración de habitantes de la corte, todos ellos preocupados por su apariencia y las mujeres sobre todo por el dinero, Quevedo alude a dos artilugios utilizados para dar consistencia a la figura: los petos para las barrigas y las pantorrillas postizas, que rellenaban esas dos partes del cuerpo flácidas por la propia vejez ${ }^{41}$. Pero el entremés que más interesa a nuestros propósitos en este ámbito es

37. viejo clueco: «Viejo bobo, carroño. Por astuto y torpe; viejo cagón; clueco y roñoso; potrilla; son desdeños» (Correas, 23610).

38. potra: «Especie de hernia o rotura interior que se causa por bajar las tripas a la bolsa de los testículos» (Aut).

39. braguero: «Género de ligadura compuesta de diferentes fajas o ramales que se atan a la cintura y pasan por debajo de las ingles, con los cuales se sostienen las quebraduras [hernias]: o para que se suelden o para que las tripas no hagan más bolsa y peso. Hay varios modos y hechuras: unos se hacen de acero batido y templado, con unas almohadillas pendientes de ciertas correas: otros se hacen de lienzo, fabricados de diversas maneras; pero todos sirven para un mismo fin» (Aut).

40. visaje: «Gesto desproporcionado o demostración reparable del rostro, con que se da a entender algún afecto o pasión interior» (Aut); «movimiento exagerado del rostro por hábito o enfermedad» (DLE).

41. Como indican Arellano y García Valdés, estos motivos aparecen en más obras quevedianas (Teatro completo, p. 360, nota 6). Por poner un ejemplo: «Ayer sobre dos astillas / 
La ropavejera, cuyo motivo central es la grotesca (y trágica) lucha entre el paso del tiempo y la vanidad humana. La protagonista es una patética mujer que en lugar de vender ropa vieja, regenta una especie de taller de reparación de cuerpos viejos, cuya especialidad son los «repuestos». Desfilan ante ella los tipos más singulares, presentados por Rastrojo, que en la segunda parte tomará protagonismo al ser él mismo un «baile viejo». Su presentación no puede ser más expresiva:

\begin{tabular}{|c|c|}
\hline Ropavejera & $\begin{array}{l}\text { Soy calcetera yo del mundo junto, } \\
\text { pues los cuerpos humanos son de punto, } \\
\text { como calza de aguja. } \\
\text { Cuando se sueltan en algunas barbas } \\
\text { puntos de canas, porque estén secretas, } \\
\text { les echo de fustán unas soletas. } \\
\quad[\ldots] \\
\text { Yo vendo retacillos de personas, } \\
\text { yo vendo tarazones de mujeres, } \\
\text { yo trastejo cabezas y copetes, } \\
\text { yo guiso con almíbar los bigotes. } \\
\text { atro completo, pp. 532-533). }\end{array}$ \\
\hline
\end{tabular}

El orgullo de su oficio, que sirve indisimuladamente a la hipocresía y al disimulo, queda bien patente, pues se atreve a desafiar al mismísimo Tiempo:
Ropavejera Ya en el mundo no hay años, pues aunque el Tiempo a averiguarlos venga, no hallará en todo el mundo quien los tenga.
(Teatro completo, p. 534).

Nuestro vejete se integra en el desfile de una serie de figuras con requerimientos macabros: una mujer que quiere comprar muelas postizas, una vieja que quiere hervirse la cara con lejía para borrar sus arrugas, otra que va en busca de talle, manos y cara nuevos, y un capón en busca de barba y bigote postizos. En esta línea, nuestro personaje, don Crisóstomo, desea unas piernas nuevas y teñirse el pelo y la barba con (mójili», sustancia equivalente a un tinte:

andaba el señor Bicoca, / y hoy, la barriga a la boca, / lleva ya las pantorrillas» (Quevedo, Poesía original, núm. 652). 


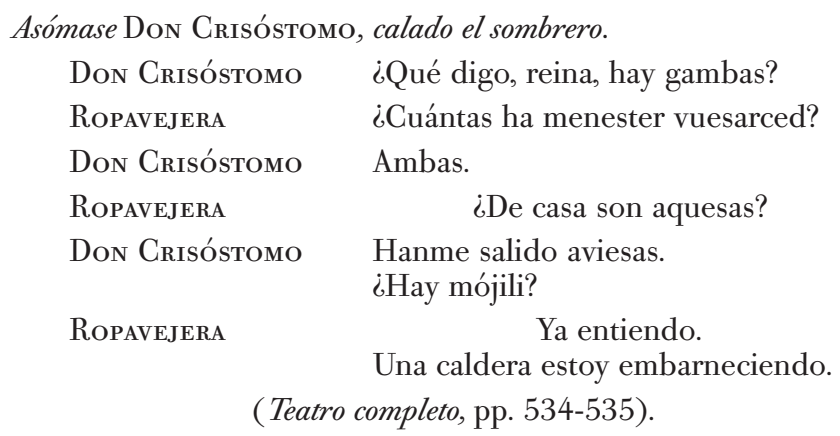

El paso del tiempo fue tratado de forma profunda y seria por Quevedo, como es sabido, aunque también de modo burlesco en algunos poemas satíricos, como «Lindo gusto tiene el tiempo» y «Hoy la trompeta del juicio» ${ }^{42}$. Sin embargo, pocas veces se llega al grado de sarcasmo de esta pieza, que entre risas y veras, no deja de recordar al lector de entonces y de ahora que el paso del tiempo es realmente inexorable. La autodefinición de la grotesca mujer como «ropavejera de la vida» (Teatro completo, p. 531) es un envite entre cómico y trágico ${ }^{43}$ a algo que metafísicamente es y será imposible: detener el tiempo. Lo que ella vende, pues, solo son (apariencias», recursos efímeros para encubrir una realidad. Una vez más, estos vejetes de los que el espectador se ríe logran detener el paso del tiempo en apariencia, pero el problema es que el engaño barroco, tan halagüeño para la vista y el oído, no puede con lo que a la razón es evidente.

Basten estas reflexiones al hilo de selectos pasajes entremesiles para corroborar que también en la figura del viejo logró el arte de don Francisco (fertilizar el entremés), en expresión conocida de Asensio ${ }^{44}$. Frente a la vejez entendida por el autor en otras obras como etapa vital de reflexión y sabiduría, y especialmente valiosa por la experiencia adquirida ${ }^{45}$, aquí es en esencia un motivo de solfa, y la presencia del ancia-

42. Así lo indican Arellano y García Valdés, 2001, p. 26. Para estos poemas, ver Poesía original, núm. 757 y 869.

43. Muy acertada me parece la opinión de Arellano y García Valdés acerca de esta pieza: «una truculenta parodia del tempus fugit [...] mezcla asombrosamente la risa y el horror» (Teatro completo, p. 81).

44. Ver Asensio, 1971, p. 178: «Quevedo fertilizó el entremés, directa e indirectamente, de tres modos diferentes: con sus piezas originales; con el almacén de tipos y figuras, de situaciones y ocurrencias que puso a disposición de los cómicos; y últimamente con la ejemplar técnica literaria que aplicó a la pintura del hombre».

45. Un caso claro de dignificación de la ancianidad es la figura del Desengaño de $E l$ mundo por de dentro, personificado en un viejo juicioso, del que se puntualiza que no es ridículo: «Era un viejo venerable en sus canas, maltratado, roto por mil partes el vestido y pisado; no por eso ridículo, antes severo y digno de respeto" (Quevedo, Los sueños, ed. Arellano, p. 274). El sabio viejo critica un poco más adelante a los ancianos que se tiñen, buscando solo la apariencia: «¿No ves los viejos hipócritas de barbas, con las canas envainadas en tinta, querer en todo parecer muchachos? ¿No ves a los niños preciarse de 
no equivale a la de un pelele caricaturizado. Sin embargo, es cierto que en contraste con su homóloga femenina, la vieja en todas sus variantes, la sátira es menor cuantitativa y cualitativamente e incluso en algún momento se puede adivinar la intención de suscitar cierta compasión hacia su desventura física y hacia cierto maltrato deparado por una mujer joven, sea esposa o no. Por otra parte, y desde el punto de vista de la constitución del personaje, hemos mostrado que los vejetes quevedianos entroncan con ciertas figuras de los entremeses de Lope de Rueda y de Cervantes. Respecto al primero, Quevedo seguirá la técnica de fundir la figura del viejo con la de otro personaje, como, por ejemplo, en La venta, en la que el viejo Corneja es a la vez un ventero ladrón, o en El marión, en la que el viejo es un padre que custodia la honra de su hijo. La inspiración cervantina es nítida en la figura del viejo celoso y del anciano enfermo que soporta los desdenes de su joven mujer. Don Francisco no añade al personaje ningún rasgo nuevo ni particular pero consigue un paródico y peculiar desfile de vejetes que arrastran sus taras y sus desventuras en medio de la chanza de sus familiares y deudos y por ende de toda la sociedad. Esta figura quevedesca será un eslabón más en el tipo entremesil del vejete de la segunda mitad del xvir, si bien en esta etapa el personaje se aligerará de esa carga negativa de sarcasmo e ironía, marca del gran autor madrileño, para desplegar toda la fuerza de su comicidad y provocar, sin más pretensiones, la risa del espectador.

\section{Bibliografía}

Arellano, Ignacio, "Anotación filológica de textos barrocos: el "Entremés de la vieja Muñatones" », en Notas y estudios filológicos, ed. José Fradejas et al., Pamplona, Universidad Nacional de Educación a Distancia (sede de Navarra), 1984, pp. 87-117.

Arellano, Ignacio, Poesía satírico-burlesca de Quevedo, Pamplona, Universidad de Navarra, 1984.

Arellano, Ignacio, y Celsa Carmen García Valdés, «El Entremés del marido pantasma, de Quevedo", La Perinola, 1, 1997, pp. 41-68.

Arellano, Ignacio, y Celsa Carmen García Valdés, «Entremés de la ropavejera, de Quevedom, La Perinola, 5, 2001, pp. 25-38.

Arellano, Ignacio, y Celsa Carmen García Valdés, «Entremés de la venta, de Quevedom, La Perinola, 10, 2006, pp. 345-359.

Arellano, Ignacio y Celsa Carmen García Valdés, “Prólogo» a Teatro completo. Francisco de Quevedo, Madrid, Castalia, 2011.

Arellano, Ignacio, «Modelos femeninos en la poesía de Quevedo», La Perinola, 16, 2012, pp. 47-63.

Artigas, Miguel, Teatro inédito de don Francisco de Quevedo, Madrid, rae, 1927.

Asensio, Eugenio, Itinerario del entremés, Madrid, Gredos, 1971.

Astrana Marín, Luis, Prólogo y apéndices a Obras completas. Verso. Francisco de Quevedo, Madrid, Aguilar, 1932.

dar consejos y presumir de cuerdos? Pues todo es hipocresía» (Quevedo, Los sueños, ed. Arellano, p. 279). 
Blecua, José Manuel, «Prólogo», a Francisco de Quevedo, Obra poética, Madrid, Castalia, 1981, 4 vols.

Borrego Gutiérrez, Esther, Teatro breve de Vicente Suárez de Deza. Estudio y edición, Kassel, Reichenberger, 2000, 2 vols.

Borrego Gutiérrez, Esther, Un poeta cómico en la corte de Felipe IV. Vicente Suárez de Deza, Kassel, Reichenberger, 2002.

Borrego Gutiérrez, Esther, «De dueñas, celestinas y entremeses», en Enlaces, número 0 (2003) [ref. http://alfama.sim.ucm.es/revistas/revistasUCM.asp]

Buendía, Felicidad, Obras completas de Francisco de Quevedo, Madrid, Aguilar, 1958.

Cervantes, Miguel de, Entremeses, ed. Eugenio Asensio, Madrid, Castalia, 1970.

Correas, Gonzalo, Vocabulario de refranes y frases proverbiales, ed. Rafael Zafra, Kassel / Pamplona, Reichenberger / Universidad de Navarra, 2000.

Cotarelo y Mori, Emilio, Colección de entremeses, loas, jácara y mojigangas, Madrid, Bailly-Ballière, 1911, NBAE, vols. 17 y 18.

Cotarelo Valledor, Armando, «El teatro de Quevedo», Boletín de la Real Academia Española, 24, 1945, pp. 41-104.

Crosby, James O., En torno a la poesía de Quevedo, Madrid, Castalia 1967.

Fernández Guerra, Aureliano, Prólogo a su edición de Quevedo, Obras, Madrid, Rivadeneyra, 1921 y 1923, BAE, vols 23 y 48.

Hernández Araico, Susana, «El teatro breve de Quevedo y su arte nuevo de hacer ridículos en las tablas: lego-pro-menos a una representación riescénica», La Perinola, 8, 2004, pp. 201-234.

Hernández Vargas, Jaime, «Dos viejas celestinas y hechiceras en la lírica quevediana: fisonomía y retratos sociales como instrumentos punitivos», $L a$ Perinola, 19, 2015, pp. 161-180.

Huerta Calvo, Javier, Teatro breve de los siglos XVI y XVII, Madrid, Taurus, 1985.

Jauralde Pou, Pablo, Francisco de Quevedo (1580-1645), Madrid, Castalia, 1998.

La Barrera y Leirado, Cayetano Alberto, Catálogo bibliográfico y biográfico del teatro antiguo español, Madrid, Rivadeneyra, 1860.

Lobato López, María Luisa, Calderón de la Barca. Teatro cómico breve, Kassel, Reichenberger, 1989.

Maestro, Jesús G., “Las formas de lo cómico en los entremeses de Quevedo», $L a$ Perinola, 12, 2008, pp. 79-105.

Mancini, Guido, Gli entremeses nell'arte di Quevedo, Pisa, Goliardica, 1955.

Quevedo, Francisco de, Obra poética, ed. José Manuel Blecua, Madrid, Castalia, 1981, 4 vols.

Quevedo, Francisco de, Poesía original completa, ed. José Manuel Blecua, Barcelona, Planeta, 1981.

Quevedo, Francisco de, Prosa festiva completa, ed. Ignacio Arellano y Celsa Carmen García Valdés, Madrid, Cátedra, 1993.

Quevedo, Francisco de, Los sueños, ed. Ignacio Arellano, Madrid, Cátedra, 1996.

Quevedo, Francisco de, Teatro completo, ed. Celsa Carmen García Valdés, Madrid, Cátedra, 2011.

Rueda, Lope de, Pasos, ed. José Luis Canet, Madrid, Castalia, 1992.

Sáez Raposo, Francisco, y Javier Huerta Calvo, "Francisco de Quevedo», en Historia del teatro breve en España, dir. Javier Huerta Calvo, Madrid / Frankfurt am Main, Iberoamericana / Vervuert, 2008, pp. 183-201.

Schwartz, Lía, Quevedo: discurso y representación, Pamplona, Eunsa, 1986. 